\title{
Identifying Persons at Risk for PTSD After Trauma with TSQ in The Netherlands
}

\author{
A. M. M. Dekkers · M. Olff · G. W. B. Näring
}

Received: 14 July 2008/Accepted: 16 April 2009/Published online: 25 April 2009

(C) The Author(s) 2009. This article is published with open access at Springerlink.com

\begin{abstract}
In The Netherlands about $80 \%$ of the population experience a traumatic event while about $14 \%$ develop post traumatic stress disorder (PTSD). Considering this high prevalence the prevention or early treatment of posttraumatic stress is important from a health as well as costbenefit perspective. The aim of this study was to examine whether we could identify subjects at risk of developing PTSD. We included 100 Dutch victims of different civil traumas that contacted the Victim Support Foundation. The trauma screening questionnaire (TSQ), was used as a screening tool. The results show that a cut-off score of 7 on the TSQ correctly identified most subjects with PTSD. We found a moderate positive correlation between PTSD and the severity of complaints. We also found a significant relationship between the TSQ and depression symptoms. This study indicates that the Dutch version of the TSQ is a useful instrument for identifying future cases of PTSD.
\end{abstract}

Keywords Post traumatic stress disorder - Trauma . Screening

\section{Introduction}

In The Netherlands about $80 \%$ of the population experience a traumatic event while about $14 \%$ develop post

\footnotetext{
A. M. M. Dekkers · G. W. B. Näring ( $\square)$

Department of Clinical Psychology, Behavioural Science Institute, Radboud University Nijmegen, P.O. Box 9104, 6500 HE Nijmegen, The Netherlands

e-mail: g.naring@psych.ru.nl

M. Olff

Center for Psychological Trauma, Amsterdam Medical Center, University of Amsterdam, Amsterdam, The Netherlands
}

traumatic stress disorder (PTSD; Olff and de Vries 2004, Nov.). The core symptoms of PTSD are persistent reexperiencing of the traumatic event, persistent avoidance of stimuli associated with the trauma, numbing of general responsiveness and persistent symptoms of increased arousal. These symptoms are associated with clinically significant distress and impairment in social, occupational or other important areas of functioning (American Psychiatric Association 2000). PTSD is a chronic and disabling disorder (Olff and de Vries 2004, Nov.). The national comorbidity study (NSC; Kessler et al. 1995) reported an average recovery period of 36 months for people who had professional treatment and 64 months for people without such help. Patients with PTSD often suffer from comorbid disorders such as depression, other anxiety disorders, and alcohol and drugs abuse (Brewin et al. 2000; Breslau 2001; Foa et al. 2006; Kessler et al. 1995; Norris et al. 2002; Zayfert et al. 2002). PTSD is also associated with increased health care cost to the society (Walker et al. 2003). Considering the high prevalence early detection of subjects at risk may help to prevent PTSD through early interventions (Sijbrandy et al. 2007).

The screening instruments for identifying victims at risk for PTSD that have been developed, were mostly based on risk factors. However, as risk factors are not consistent across studies and may be sample-dependent, Brewin et al. (2000) argued that individual symptoms might be a more effective tool for screening. In his study, Brewin (2005) reviewed 14 screening instruments for PTSD and concluded that the overall efficiency of all screening instruments was good. The 10-item TSQ (Brewin et al. 2002) performed particularly well. In the present study, the Dutch version of the TSQ was validated. In order to assess the specificity of the instrument, we not only assessed how well the TSQ predicted PTSD, but also how well it 
predicted other anxiety disorders and depression. Our hypothesis was that the TSQ would be an effective screener for PTSD.

The identification of subjects at risk for PTSD is important from a health as well as cost-benefit perspective. This makes prevention or early treatment of PTSD possible. The aim of this study was, therefore, to examine whether we could identify subjects at risk of developing PTSD who were referred themselves to Victim Support Foundation.

\section{Method}

\section{Participants}

Participants were recruited in the Victim Support Foundation in the cities of Nijmegen, Arnhem and Ede in The Netherlands. They were victims of several types of crimes, violent, and sexual assaults, car accidents and other crimes like stalking. One hundred persons participated in the first part (T1) when the TSQ was completed. The second part of this study (T2) took place after a month and was completed by 76 participants. In this part, the Clinician Administered PTSD Scale (CAPS) was administered. Twenty-four subjects did not participate in $\mathrm{T} 2$ for various reasons. Eleven persons could not be contacted for T2, despite two or more telephone calls. A further 13 persons gave various reasons for not participating. The most common stated reason was that they found it difficult to talk about the traumatic event. Two persons said that they did not have time to complete the second part. At T2, the CAPS, Impact of Event ScaleRevised (IES-R), the Hospital Anxiety and Depression Scale (HADS) and the Mini International Neuropsychiatric Interview (MINI) were administered. The participants' characteristics are given in Table 1.

Table 1 Characteristics of the participants

\begin{tabular}{lll}
\hline & $T_{1}$ & $T_{2}$ \\
\hline$N$ & 100 & 76 \\
Gender (male/female) & $36 / 64$ & $28 / 48$ \\
Age (years) & $37(16.5)$ & $36.8(16.5)$ \\
Type of trauma & & \\
$\quad$ Assault & 64 & $48(63.2 \%)$ \\
$\quad$ Accident & 27 & $23(30.3 \%)$ \\
$\quad$ Sexual assault & 3 & $2(2.6 \%)$ \\
$\quad$ Other & 6 & $3(3 \%)$ \\
Trauma screening questionnaire & $6.38(3.1)$ & $6.4(3.0)$ \\
Social support (yes/no) & $89 / 11$ & $70(92.1 \%) / 6(7.9 \%)$ \\
Prior trauma (yes/no) & $45 / 55$ & $30(39.5 \%) / 6(60.5 \%)$ \\
Injury (yes/no) & $53 / 47$ & $40(52.6 \%) / 36(47.4 \%)$ \\
\hline
\end{tabular}

For age and TSQ means are given with SD's in parentheses
There were a few differences between the drop-outs and the participants in the T2 sample. In the drop-out group, there were fewer victims of car accidents and unspecified crimes in comparison with the T2 sample. The drop-outs were more likely to report a less socially supportive context and repeated past victimization. On the other hand, the dropouts reported that the impact of the incident had been less life-threatening.

\section{Measures}

\section{Trauma Screening Questionnaire}

The trauma screening questionnaire (TSQ; Brewin et al. 2002) is a PTSD screening instrument and was adapted from the PTSD symptom scale-self report (Foa et al. 1993). The TSQ is a ten-item instrument consisting of five reexperiencing and five arousal items from the DSM IV (American Psychiatric Association 2000) PTSD criteria. Re-experiencing is tapped with items 'upsetting thoughts or memories about the event that have come into your mind against our will', 'upsetting dreams about the event', 'acting or feeling as though the event were happening again', 'feeling upset by reminders of the event', and 'bodily reactions (such as fast heartbeat, stomach churning, sweatiness, dizziness) when reminded of the event'. Arousal items are 'difficulty falling or staying asleep', 'irritability or outbursts of anger', 'difficulty concentrating', 'heightened awareness of potential dangers to yourself and others', and 'being jumpy or being startled at something unexpected'. Participants were asked whether or not they had experienced each symptom at least twice in the past week. Brewin et al. (2002) found an optimal cutoff score of 6 .

\section{Clinician Administered PTSD Scale}

The Dutch version of the CAPS (Blake et al. 1995) was used to make a PTSD diagnosis. This structured interview measures the frequency and intensity of each PTSD symptom and consists of the 17 items of PTSD symptoms as listed in the DSM IV and a further eight related symptoms such as guilt. Hovens et al. (1994) validated the CAPS and concluded that the use of the CAPS enables a direct and reliable PTSD diagnosis.

\section{Impact of Event Scale-Revised}

The IES-R (Horowitz et al. 1979; Weiss and Marmar 1997) is a self-report measure that consists of eight intrusion items, eight avoidance items and six hyperarousal items. Each item consists of a 4-point Likert scale ranging from 0 (not at all) to 4 (a lot). The internal consistency for the total 
and for the three subscales intrusion, avoidance and hyperarousal, was high (Creamer et al. 2003). In the present study, the IES-R was used as an indicator of subjective stress.

\section{Hospital Anxiety and Depression Scale}

The HADS (Zigmond and Snaith 1983) is a screening instrument for anxiety disorders and depression, and consists of seven anxiety and seven depression items. The reliability in a sample of Dutch traumatized persons was high, with Cronbach's alphas ranging from .71 to .91 (Spinhoven et al. 1997). A score of at least 8 on the anxiety scales indicates a probable anxiety disorder, and a score of at least 8 on the depression scale indicates probable depression. The HADS is useful in precluding anxiety disorders or depression, but it is not suitable for diagnosing these disorders.

In this study, the HADS was used to screen subjects for depression or an anxiety disorder. When subjects had a minimal score of 8 , the MINI was used to get a reliable DSM IV classification.

\section{Mini International Neuropsychiatric Interview}

The MINI (Sheehan et al. 1998) is a semi-structured interview for the diagnosis of 19 different disorders from the DSM IV and de ICD-10. The concordance between diagnoses made with the MINI and diagnoses made with longer clinical interviews is high (Sheehan et al. 1998). In this study, the MINI was used to diagnose mood disorders and anxiety disorders.

\section{Procedure}

Participants were recruited in Victim Support offices in the cities of Nijmegen, Arnhem and Ede in The Netherlands. Victim Support is an institution that provides emotional, legal and practical support to victims after a crime or an accident. The victims were first contacted by phone by a support volunteer. Then, a researcher (A.D.) made a second call to ask the victims whether they would like to participate in the study. After informed consent was obtained, the Dutch version of the TSQ was then administered (T1). Once completed, participants were reminded that they would be contacted again in a month to complete the second part of this study (T2). After a month, they were contacted again to administer the CAPS, the IES-R and the HADS. Results showing a cut-off of eight were taken to indicate depression or an anxiety disorder. Subjects with such results completed the MINI to get a reliable diagnosis. Subjects with a diagnosis were advised to contact their general practitioner.
Analysis

Sensitivity and specificity of the TSQ were calculated. Sensitivity is the probability that a person with a PTSD diagnosis will have a positive test score. Specificity is the probability that a person without a PTSD diagnosis will have a negative test score. The positive and negative predictive power were also calculated. The positive predictive power is the probability that a person with a positive test score will have a PTSD diagnosis. The negative predictive power is the probability that someone with a negative test score will not have a PTSD diagnosis. The positive and negative predictive powers are influenced by the prevalence of a disorder (Brewin et al. 2002). Second, we calculated Pearson's correlation between the total TSQ score and severity of complaints. Finally, we investigated the relationship between the TSQ score and the presence of depression and anxiety disorders with contingency tables.

\section{Approval}

The Institutional Review Board of the Behavioral Science Institute of the Radboud University approved the present study.

\section{Results}

In this study, 76 subjects participated at T2, $48(63 \%)$ women and $28(37 \%)$ men. The characteristics of the subjects are given in Table 1 . Most subjects $(63 \%)$ were victims of violence, 23 subjects $(30 \%)$ had had a traffic accident, two (3\%) were victims of a sexual crime and three subjects $(4 \%)$ were victims of other offences such as burglary. The average time between the offence and the administration of the TSQ was 2 weeks. After 1 month 31 of 76 participants (41\%) met the DSM IV criteria for PTSD and the reliability was good $(\alpha=.85)$.

\section{Sensitivity and Specificity}

To obtain sensitivity and specificity, we performed a ROCAnalysis. Table 2 gives an overview of the possible cut-off scores with the associated sensitivity, specificity and the positive and negative predictive power. The ROC curve is given in Fig. 1.

At a cut-off score of 7, we found a high sensitivity and specificity in combination with a high overall efficiency. At cut-off of 7, 87.1\% subjects with PTSD had been correctly identified through a positive test result and $68.9 \%$ of the subjects without PTSD were identified correctly by the TSQ with a negative test result. The positive predictive power at cut-off of 7 was .66. The negative predictive value 
Table 2 Cut-off scores with corresponding sensitivity, specificity, positive and negative predictive power and overall efficiency

\begin{tabular}{llllll}
\hline TSQ-score & Sensitivity & Specificity & $\begin{array}{l}\text { Positive predictive } \\
\text { power }\end{array}$ & $\begin{array}{l}\text { Negative predictive } \\
\text { power }\end{array}$ & Overall efficiency \\
\hline 5 & .94 & .44 & .54 & .91 & .64 \\
6 & .94 & .56 & .59 & .93 & .71 \\
7 & .87 & .69 & .66 & .89 & .76 \\
8 & .81 & .76 & .69 & .85 & .78 \\
\hline
\end{tabular}

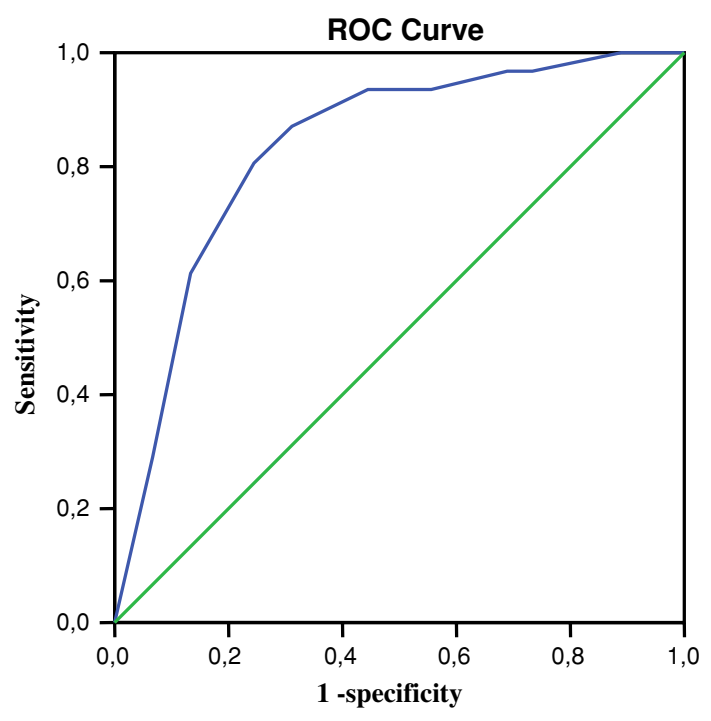

Fig. 1 ROC curve of the TSQ

at cut-off of 7 was high, .89. The overall efficiency was also high, .76.

\section{Severity of Complaints}

The correlation between the TSQ and the IES-R correlation was high, $r=.59, P=.01$ (Cohen 1988).

TSQ and Depression and Other Anxiety Disorders

There was a non-significant correlation between the total TSQ score and other anxiety disorders $\left(\chi^{2}(10)=13.77\right.$, $P=.18)$. The correlation between the TSQ and depression was significant $\left(\chi^{2}(10)=19.42, P=.04\right)$, which indicates that the TSQ and depression are related.

\section{Discussion}

The Dutch version of the TSQ seems to be an effective instrument to screen for people at risk of PTSD. Sensitivity and specificity were balanced best at a cut-off score of 7 . At a cut-off score of 8 , the sensitivity was much lower, .81 instead of .87. From a prevention perspective, it is important to identify as many persons at risk for PTSD as possible and therefore a higher sensitivity is more important than a higher specificity. However, Brewin et al. (2002) suggested a cut-off score of 6 . In this study at a cutoff of 6 , sensitivity and the positive predictive power had a significant higher value in comparison to the specificity and the negative predictive power. At cut-off score of $6,94 \%$ of the people with PTSD were identified correctly.

The second aim of this study was to investigate whether the TSQ can predict the severity of PTSD symptoms. The correlation between the TSQ and the symptoms was large and positive. The TSQ is a good instrument for predicting the severity of complaints.

The third and last aim of this study was to investigate whether the TSQ can predict other anxiety disorders and mood disorders. There was a non-significant relation between the TSQ and other anxiety disorders, but a significant correlation was found between the TSQ and depression. As depression is frequently a co-morbid disorder in subjects with PTSD, this finding is not surprising (O'Donnell et al. 2004). Furthermore, there has to be some overlap as two items ('Difficulty falling or staying asleep' and 'Difficulty concentrating') of the TSQ are also symptoms of depression.

The sample in this study, compared with those in others, was heterogeneous. Earlier research used homogenous populations such as victims of a train crash or a car accident (Brewin et al. 2002), which can result in different optimal cut-off score. It has been suggested that trauma severity has implications for the development of PTSD. It is possible that cut-off scores have to be established separately for various populations.

There were important differences between the subjects who participated in the second part and the drop-outs. First, the drop-outs consisted of fewer people who were the victim of a car accident. Second, the subjects in the dropout group reported that they did not have a supportive environment. Previous research suggested that a lack of a supportive environment is a risk factor for the development of PTSD. Third, drop-outs reported that they had been victimized repeatedly. This is also a risk factor for PTSD. Finally, subjects who participated in this study reported 
more often that they had experienced the event as traumatic. Most likely, people in the drop-out group are avoiding stimuli that can cause re-experiencing the traumatic event. These people are more likely to meet the DSM criteria for PTSD.

This study was limited in time due to practical considerations. We chose to interview subjects for the second part of the study after a month. We recommend a study with a duration of at least 1 year to investigate the course of PTSD-related symptoms. Follow-ups can be done at 1, 3, 6, and 12 months intervals.

It may be useful to distinguish between subjects with PTSD, without PTSD and with a partial PTSD. People who do not meet the DSM criteria for PTSD can have significant impairments in functioning because of the stressrelated symptoms. In the literature, partial PTSD is also known as subthreshold PTSD or Anxiety disorder not otherwise specified (Angst 1997; Foa et al. 2000). Further research is needed to investigate what the course of these stress-related symptoms is in the partial PTSD group.

In this study we found that people at risk for PTSD can be screened effectively. It is important to screen people at risk as soon as possible to prevent the development of chronic complaints such as PTSD. Instead of giving direct support to a large number of victims, it may be more effective to give targeted and higher quality support to those at risk (Sijbrandy et al. 2007).

Open Access This article is distributed under the terms of the Creative Commons Attribution Noncommercial License which permits any noncommercial use, distribution, and reproduction in any medium, provided the original author(s) and source are credited.

\section{References}

American Psychiatric Association. (2000). Diagnostic and statistical manual of mental disorders (4th TR ed.). Washington, DC: American Psychiatric Association.

Angst, J. (1997). Depression and anxiety: Implications for nosology, course, and treatment. The Journal of Clinical Psychiatry, 58, 3-5.

Blake, D. D., Weathers, F. W., Nagy, L. M., Kaloupek, D. G., Gusman, F. D., Charney, D. S., et al. (1995). The development of a clinician-administered PTSD scale. Journal of Traumatic Stress, 8(1), 75-90.

Breslau, N. (2001). Outcomes of posttraumatic stress disorder. The Journal of Clinical Psychiatry, 62(Suppl. 17), 55-59.

Brewin, C. R. (2005). Systematic review of screening instruments for adults at risk of PTSD. Journal of Traumatic Stress, 18(1), 53-62. doi:10.1002/jts.20007.

Brewin, C. R., Andrews, B., \& Valentine, J. D. (2000). Meta analysis of risk factors for post-traumatic stress disorder in traumaexposed adults. Journal of Consulting and Clinical Psychology, 68, 748-766. doi:10.1037/0022-006X.68.5.748.

Brewin, C. R., Rose, S., Andrews, B., Green, J., Tata, P., McEvedy, C., et al. (2002). Brief screening instrument for post-traumatic stress disorder. The British Journal of Psychiatry, 181, 158-162.
Cohen, J. (1988). Statistical power analysis for the behavioral sciences (2nd ed.). Hillsdale, NJ: Lawrence Erlbaum Associates.

Creamer, M., Bell, R., \& Failla, S. (2003). Psychometric properties of the impact of event scale-revised. Behaviour Research and Therapy, 41, 1489-1496. doi:10.1016/j.brat.2003.07.010.

Foa, E. B., Riggs, D. S., Dancu, C. V., \& Rothbaum, B. O. (1993). Reliability and validity of a brief instrument for assessing posttraumatic stress disorder. Journal of Traumatic Stress, 6(4), 459473.

Foa, E. B., Kessler, R. C., McFarlane, A. C., \& Shalev, A. Y. (2000). Consensus statement on post-traumatic stress disorder from the international consensus group on depression and anxiety. The Journal of Clinical Psychiatry, 61(Suppl. 5), 6066.

Foa, E. B., Stein, D. J., \& McFarlane, A. C. (2006). Symptomatology and psychopathology of mental health problems after disaster. The Journal of Clinical Psychiatry, 67(Suppl. 2), 15-25.

Horowitz, M., Wilner, N., \& Alvarez, W. (1979). Impact of event scale: A measure of subjective stress. Psychosomatic Medicine, 41(3), 209-218.

Hovens, J. E., van der Ploeg, H. M., Klaarenbeek, M. T. A., Bramsen, I., Schreuder, J. N., \& Vladar Rivero, V. V. (1994). The assessment of posttraumatic stress disorder with the clinicianadministered PTSD scale: Dutch results. Journal of Clinical Psychology, 50(3), 325-340. doi:10.1002/1097-4679(199405) 50:3<325::AID-JCLP2270500304>3.0.CO;2-M.

Kessler, R. C., Sonnega, A., Bromet, E., Huhes, M., \& Nelson, C. B. (1995). Posttraumatic stress disorder in the national comorbidity survey. Archives of General Psychiatry, 52, 1048-1060.

Norris, F. H., Friedman, M. J., Watson, P. J., Byrne, C. M., Diaz, E., \& Kaniasty, K. (2002). 60,000 Disaster victims speak: Part I. An empirical review of the empirical literature, 1981-2001. Psychiatry, 65(3), 207-239.

O’Donnell, M. L., Creamer, M., \& Pattison, P. (2004). Posttraumatic stress disorder and depression following trauma: Understanding comorbidity. The American Journal of Psychiatry, 161, 13901396. doi:10.1176/appi.ajp.161.8.1390.

Olff, M., \& de Vries, G. J. (2004). Prevalence of trauma and PTSD in The Netherlands. Paper presented at the 20th annual meeting of the international society for traumatic stress studies [ISTSS], New Orleans.

Sheehan, D. V., Lecrubier, Y., Harnett-Sheehan, K., Amorim, P., Janavs, J., Weiller, E., et al. (1998). The mini-international neuropsychiatric interview (MINI): The development and validation of a structured diagnostic psychiatric interview for DSM IV and ICD-10. The Journal of Clinical Psychiatry, 59(Suppl. 20), 22-33.

Sijbrandy, M., Olff, M., Reitsma, J. B., Carlier, I. V. E., de Vries, M. H., \& Gersons, B. P. R. (2007). Treatment of acute posttraumatic stress disorder with brief cognitive behavioral therapy: A randomised, controlled trial. The American Journal of Psychiatry, 164, 82-90. doi:10.1176/appi.ajp.164.1.82.

Spinhoven, P. H., Ormel, J., Sloekers, P. P. A., Kempen, G. I. J. M., Speckens, A. E. M., \& van Hemert, A. M. (1997). A validation study of the hospital anxiety and depression scale (HADS) in different groups of Dutch subjects. Psychological Medicine, 27, 363-370. doi:10.1017/S0033291796004382.

Walker, E. A., Katon, W., Russo, J., Ciechanowski, P., Newman, E., \& Wagner, A. W. (2003). Health care costs associated with posttraumatic stress disorder symptoms in women. Archives of General Psychiatry, 60(4), 369-374. doi:10.1001/archpsyc. 60.4.369.

Weiss, D. S., \& Marmar, C. R. (1997). The impact of event scalerevised. In J. P. Wilson \& T. M. Keane (Eds.), Assessing psychological trauma and PTSD: A practitioner's handbook (2nd ed., pp. 399-411). New York, NY: Guildford Press. 
Zayfert, C., Becker, C. B., Unger, D. L., \& Shearer, D. K. (2002). Comorbid anxiety disorders in civilians seeking treatment for post-traumatic stress disorder. Journal of Traumatic Stress, 15(1), 31-38. doi:10.1023/A:1014379127240.
Zigmond, A. S., \& Snaith, R. P. (1983). The hospital anxiety and depression scale. Acta Psychiatrica Scandinavica, 67, 361-370. doi:10.1111/j.1600-0447.1983.tb09716.x. 